\title{
Fat content in pericardial suction blood and the efficacy of spontaneous density separation and surface adsorption in a prototype system for fat reduction
}

\author{
Micael Appelblad, ECCP, PhD, and Karl Gunnar Engström, MD, PhD, FRCS
}

Objective: Fat embolization to the brain is a potential problem in cardiac surgery, assumed to originate from retransfused pericardial suction blood. Our aim was to measure the fat content in pericardial suction blood and to determine how it can be reduced by simple spontaneous density separation and surface absorption.

Methods: Pericardial suction blood was collected during routine coronary bypass procedures and analyzed for blood-suspended fat and plastic surface binding. A single-chamber bag $(\mathrm{n}=10)$ was compared with a fat-reducing system having a stacked 2-chamber design $(\mathrm{n}=10)$. The fat-reducing system was also tested experimentally $(\mathrm{n}=12)$ with heat-extracted liquid wound fat $(1.25 \%)$ mixed with mediastinal drain blood.

Results: Pericardial suction blood contained $1.5 \mathrm{~mL}(0.63 / 2.19)$ of fat suspended in $418 \mathrm{~mL}$ (269/631) of blood (median and quartiles). Surface-bound fat accounted for $24 \%$ (12/35). Experimental analysis of the new system revealed an $83 \%$ (71/92) fat-reduction rate $(P<.001)$. This rate was confirmed under clinical conditions, suggesting $80 \%$ reduction $(72 / 86 ; P=.001)$. The fat-reducing system also gave a small but significant red blood cell concentrating effect $(P=.001)$.

From the Department of Surgical and Perioperative Science, Cardiothoracic Surgery Division, University Hospital of Umeå, Sweden.

This work was supported by the Heart Foundation of Northern Sweden. The study had no commercial funding, except that the former manufacturer, Polystan A/S, Denmark, kindly provided free samples of the FRS prototype. The FRS technology was owned by ESTRAB, Sweden, in collaboration with Uminovainnovation $\mathrm{AB}$, Umeå University, Sweden. Karl Gunnar Engström reports a former ownership of a patent on the reported Fat Reducing System technology, which was acquired by AstraTech AB, Molndal, Sweden.

Received for publication Jan 5, 2006; revisions received Feb 27, 2006; accepted for publication April 4, 2006.

Address for reprints: Professor Karl Gunnar Engström, Cardiothoracic Surgery, Umeå University Hospital, S-901 85 Umeå, Sweden (E-mail: gunnar.engstrom@vll.se).

J Thorac Cardiovasc Surg 2007;134:366-72 $0022-5223 / \$ 32.00$

Copyright (๑) 2007 by The American Association for Thoracic Surgery

doi:10.1016/j.jtcvs.2006.04.065
Conclusions: It was confirmed that pericardial suction blood contains fat, possibly having an embolic potential. The new system allowed fat to separate by density while pericardial suction blood was temporally retained and incubated. A significant portion of fat adheres to the plastic surface, which added to the reduction. The method appeared efficient. It is proposed that pericardial suction blood should be collected during surgery to evaluate the need for retransfusion and to allow fat reduction.

B rain damage remains a vexing problem in cardiac surgery. ${ }^{1}$ The reported incidence of stroke is about $4 \%$ for coronary artery bypass graft (CABG) procedures. ${ }^{2}$ It is suggested that aortic manipulation contributes to stroke, in particular if the ascending aorta is found to be atherosclerotic. However, stroke (type I injury) is rare in comparison with type II injury, which denotes deterioration in intellectual and cognitive functions without signs of focal lesions. ${ }^{3}$ Type II injury, here described as diffuse brain damage (DBD), has been reported to occur in more than $50 \%$ of patients at discharge after CABG surgery. ${ }^{3}$ Although frequent and therefore assumed easy to investigate, DBD is multifactorial and difficult to define. ${ }^{4}$ Microembolization of wound-fat particles is a possible DBD mechanism. Fat accumulates on the surface of blood in the pericardial cavity and is retrieved in pericardial suction blood (PSB). With the routine use of cardiopulmonary bypass (CPB), PSB is continuously recycled after passing a screen filter. PSB mixes with systemic blood in the venous reservoir and is expelled into the ascending aorta and brain circulation. This type of embolic process was identified years ago ${ }^{5}$ but later 


\author{
Abbreviations and Acronyms \\ $\mathrm{CABG}=$ coronary artery bypass graft \\ $\mathrm{CPB}=$ cardiopulmonary bypass \\ DBD = diffuse brain damage \\ FRS = fat-reducing system \\ PSB = pericardial suction blood \\ SCADs $=$ small capillary and arteriolar dilations
}

neglected until more recent studies reported fat deposits in brain vessels, described as "small capillary and arteriolar dilations" (SCADs). ${ }^{6}$ A clear relation between the appearance of SCADs and PSB retransfusion has been described in animal experiments. ${ }^{7}$ Further, the in vitro capillary flow properties of PSB plasma have been found to be severely impaired, with fat contamination as a suggested mechanism. ${ }^{8}$ It was also demonstrated that SCADs were significantly reduced when PSB was processed by washing with a cell salvage device. ${ }^{9}$

The present study aimed to evaluate the dynamics of fat behavior in blood during incubation. A simple and alternative fat-reducing system (FRS), which was tested experimentally and clinically, is proposed from these findings.

\section{Patients and Methods \\ Patients}

The study had approval from the local ethics committee, and patients signed a written consent form. For the clinical part, involving elective first-time CABG procedures, PSB was collected in a single-chamber bag $(n=10)$ or processed in a specially designed bag (eg, FRS, $\mathrm{n}=10$ ). For the experimental part, discarded pericardial fat and postoperative mediastinal blood were collected from patients having routine cardiac surgery $(n=24$ for 12 experiments; see Table 1).

\section{Surgery, Anesthesia, and CPB}

The CPB prime solution contained 1.1 L Ringer acetate, $60 \mathrm{~g}$ mannitol, and $160 \mathrm{mmol} \mathrm{NaCl}$. Heparin was added to obtain an activated clotting time exceeding 480 seconds. CPB included an integrated venous/cardiotomy hard-shell reservoir (Affinity NT; Medtronic, Tolochenaz, Switzerland). Cold antegrade crystalloid cardioplegic solution was given (St Thomas Hospital-II), and CPB used moderate hypothermia, acid-base alpha-stat regimen, and flow rate to maintain a venous saturation above $70 \%$. The CABG procedures followed routine surgical guidelines and included use of a side-biting clamp. Anesthesia included fentanyl, midazolam, propofol, pancuronium, and inhaled isoflurane.

\section{Single-chamber Bag Used for Blood Collection}

A single-chamber bag was used to measure the volume of PSB and its fat content, as reference to the FRS, and consisted of an empty 2-L infusion bag (No 9315; Fresenius Kabi AB, Uppsala, Sweden). The bag was inserted distal to the pump along the PSB cardiotomy
TABLE 1. Patient demographics and surgical data

\begin{tabular}{|c|c|c|c|c|}
\hline & \multicolumn{2}{|c|}{$\begin{array}{l}\text { Clinical study } \\
(\mathrm{n}=20)\end{array}$} & \multicolumn{2}{|c|}{$\begin{array}{c}\text { Experimental blood/ } \\
\text { fat }(n=24)\end{array}$} \\
\hline & Median & $025 / 075$ & Median & $025 / 075$ \\
\hline Sex (male \%) & 95 & & 79 & \\
\hline Age (y) & 61.5 & $56.1 / 66.5$ & 70.6 & $61.2 / 75.4$ \\
\hline Length (cm) & 174 & $170 / 178$ & 175 & $169 / 178$ \\
\hline Weight (kg) & 83 & $73 / 89$ & 76 & $72 / 94$ \\
\hline Body surface area $\left(\mathrm{m}^{2}\right)$ & 1.96 & $1.87 / 2.09$ & 1.93 & $1.86 / 2.14$ \\
\hline NYHA (I/1-5/IV) & 3 & $3 / 4$ & 3 & $3 / 4$ \\
\hline EuroSCORE (-) & 2 & $1 / 3$ & 4 & $3 / 6$ \\
\hline Vessel disease (1-3) & 3 & $2 / 3$ & 3 & $3 / 3$ \\
\hline $\begin{array}{l}\text { Left ventricular function } \\
\qquad(\mathrm{good} / 1-3 / \mathrm{bad})\end{array}$ & 1 & $1 / 2$ & 1 & $1 / 2$ \\
\hline Anastomosis (n) & 3 & $3 / 4$ & 4 & $3 / 5$ \\
\hline Surgery time (min) & 152 & $128 / 196$ & 189 & $152 / 230$ \\
\hline CPB time (min) & 61 & $54 / 91$ & 82 & $68 / 105$ \\
\hline $\begin{array}{l}\text { Aortic crossclamp time } \\
\quad \text { (min) }\end{array}$ & 35 & $27 / 44$ & 43 & $33 / 71$ \\
\hline $\begin{array}{l}\text { Lowest CPB } \\
\text { temperature }\left({ }^{\circ} \mathrm{C}\right)\end{array}$ & 34.0 & $33.7 / 34.0$ & 33.7 & $33.3 / 34.0$ \\
\hline Surgical bleeding $(\mathrm{mL})$ & 325 & $300 / 425$ & 400 & $300 / 500$ \\
\hline $\begin{array}{l}\text { Allogeneic blood } \\
\text { transfusion } \\
\text { (U/patient) }\end{array}$ & 2 & $1 / 3$ & 4 & $3 / 6$ \\
\hline Length of stay (d) & 8 & $7 / 9$ & 8 & $8 / 9$ \\
\hline
\end{tabular}

Experimental fat/blood refers to patient from whom pericardial fat tissue and mediastinal blood was collected. Experimental group also contained non-coronary artery bypass graft procedures. NYHA, New York Heart Association score (I-II-IIIA-IIIB-IV); CPB, cardiopulmonary bypass.

suction line. Air escaped the bag via a vent to the cardiotomy reservoir.

\section{Description of the FRS}

The FRS was in principle a soft-shell reservoir built around a 1/4-inch tube (Figure 1). ${ }^{10}$ The FRS had intersecting welds creating two stacked compartments, with a top chamber for blood collection and a bottom chamber mainly for blood storage, both of 750-mL volume capacity. The chambers were separated by a water-lock mechanism. Fat separated from blood during incubation by density and in addition by surface adsorption to the plastic walls. ${ }^{11,12}$ The top fraction of fat-concentrated blood $(21.4 \mathrm{~mL})$ was automatically retained by the water-lock at drainage. The reservoir and tubing were of uncoated standard-type polyvinylchloride materials, identical to that of the Polystan SAFE II Softshell Venous Reservoir (Polystan A/S, Denmark/Maquet AG, Germany).

The FRS was identically interpositioned within the PSB suction line as described for the single-chamber bag. Air escaped the FRS by a vent line, which also served as an escape route in the event of blood overfilling. In case of profound bleeding, the FRS worked with through-flow if clamps were released. A minimum 10-minute incubation was allowed in the top and bottom chambers, according to previous findings. ${ }^{11}$ At clamp release the PSB entered the cardiotomy reservoir by hydrostatic drainage. 


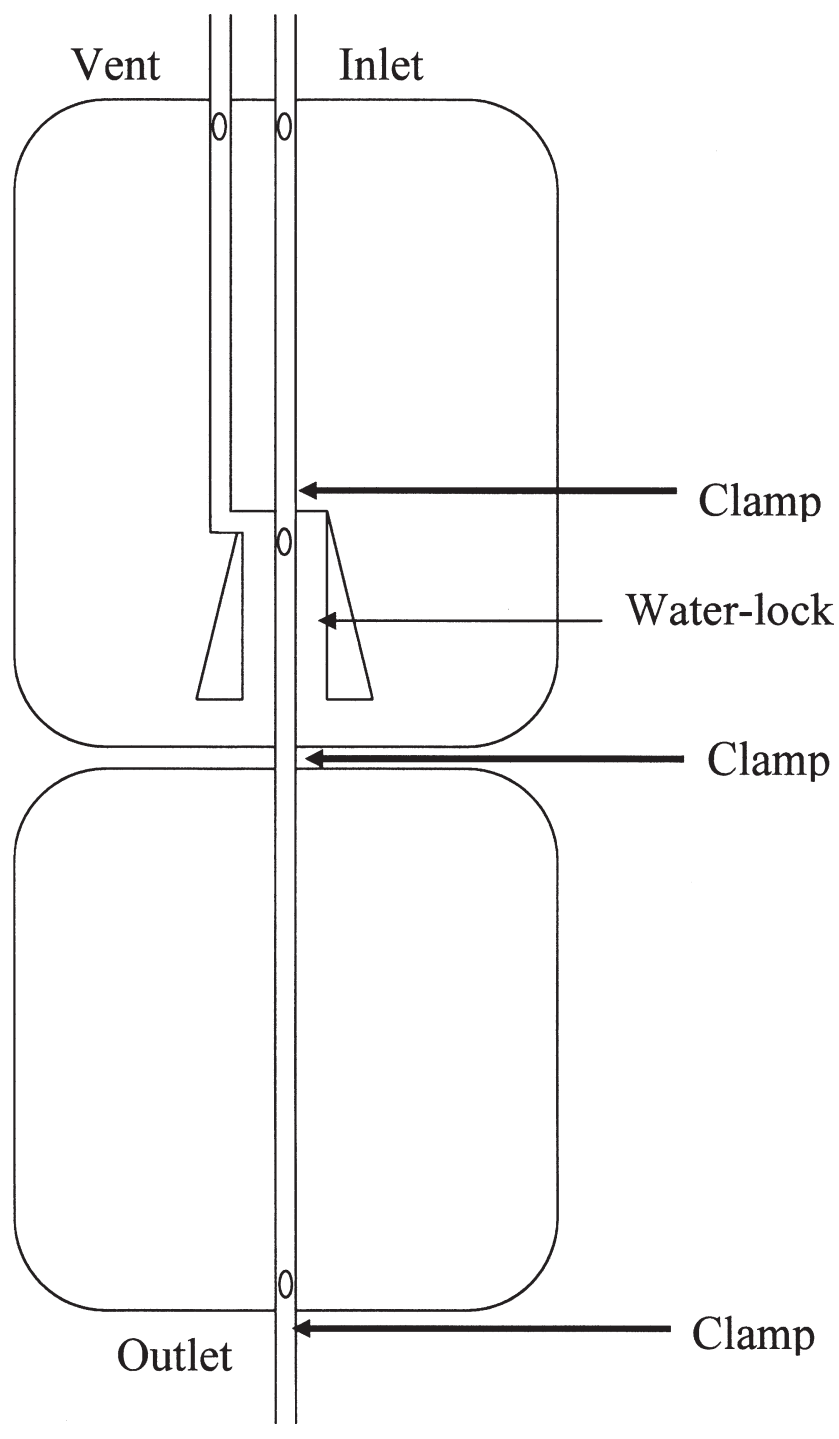

Figure 1. Schematic drawing of the fat-reducing system prototype.

\section{Clinical Study, Protocol of PSB Sampling, and Recovery of Bags}

The PSB suction was managed on the surgeon's request. PSB was here retained, which departed from our normal routine of continuous recycling. Blood from aortic venting was not pooled with PSB. In the single-chamber experiments, PSB was collected in one portion and retransfused before $\mathrm{CPB}$ weaning. At this point, a $15-\mathrm{mL}$ blood sample was drawn after thorough mixing of the bag. Venous return blood was sampled simultaneously. After surgery, the empty bag was saved for further analysis (see below). The FRS experiments had a more complex ambition with a conflict between mixing of blood to receive a representative blood sample and the necessity to allow spontaneous fat separation. Five $15-\mathrm{mL}$ blood samples were collected. The initial sampling was from the top chamber and drawn immediately before its drainage into the bot- tom chamber. This sample was aspirated from the FRS vent port (referred to as "top-chamber input"). The aspiration made the bag collapse, and the sample was a mixture of blood from outside and inside the water-lock. Mixing of blood inside the FRS was not required with this sampling technique. Venous return blood was simultaneously collected (venous control). FRS output blood was sampled just before PSB retransfusion, being subdivided into an initial PSB output and blood assumed to be retained inside the bottom chamber (bottom-chamber "output" and "retained"). In the event of more than one cycle of PSB filling and emptying, blood was collected from the first passage only, with extrapolation for any additional volumes. The FRS was recovered after use, and PSB retained by the water-lock was aspirated ("top chamber retained").

\section{Fat Measurement}

Fat was measured metrically. ${ }^{10}$ In brief, standard 150-mm Pasteur pipettes were used as centrifugation tubes. The wide end of the pipette was sealed with silicone rubber and left to harden. While held upside down, blood was loaded through the seal using a needle and positioned the same way in a modified swing-out rotor centrifuge (4K15; Sigma Laborzentrifugen $\mathrm{GmbH}$, Osterodeam-Harz, Germany). At $2000 \mathrm{~g}, 10$ minutes, and $22^{\circ} \mathrm{C}$, fat accumulated in the tapered tip of the pipette, which amplified its volume in relation to its wide barrel with plasma and blood cells. Pipettes (S/N 110601; Tamro MedLab, Mölndal, Sweden) of the same lot number were calibrated for volume-versus-distance and expressed in three linked equations considering the narrow conical tip, cone, and barrel, respectively. The hematocrit value was also recorded.

The measurement of surface-bound fat was designed to avoid previously described artifacts ${ }^{10}$ and was here measured by weight before and after detergent washing. A geometrically defined template was used to cut out 8 sheets from the recovered bags, for the FRS subdivided between the top and bottom chambers. The fatcoated surface was hydrophobic to blood, although any such remains were gently absorbed by soft cellulose tissue. The sheets were allowed to dry for 24 hours followed by weighing. Adherent fat was removed by scrubbing in water at $38^{\circ} \mathrm{C}$ with $0.3 \%$ added laboratory detergent (Extra; Rekal AB, Gnesta, Sweden). The sheets were left to redry and were reweighed. The reduction in weight equaled the amount of bound fat, expressed per area. The inside surface of the bags, and for FRS the top and bottom chambers, was geometrically measured to extrapolate the total amount of plastic-bound fat.

\section{Experimental Study: Laboratory Evaluation of the FRS}

The FRS fat separation was experimentally simulated by a defined blood/fat mixture. Fat was derived from discarded pericardial tissue, removed to gain access to the left internal thoracic artery. Liquid fat was extracted at $200^{\circ} \mathrm{C}$ for 10 minutes, which simulated fat melting by electrocautery. ${ }^{11}$ Blood was collected from discarded mediastinal drain containers (Affinity NT/CVR; Medtronic, Tolochenaz, Switzerland). Blood was prefiltered through a 200- $\mu \mathrm{m}$ screen filter (Mediplast AB, Malmö, Sweden), $10 \mathrm{E} / \mathrm{mL}$ heparin added, and $250 \mathrm{~mL}$ was mixed with liquid fat to yield $1.25 \%$ volume concentration. This concentration was selected to gain maximum resolution, considering the pipette geometry used 
TABLE 2. PSB-related data, subdivided into single-chamber and FRS

\begin{tabular}{|c|c|c|c|c|c|c|c|}
\hline & \multicolumn{2}{|c|}{ Merged $(n=20)$} & \multicolumn{2}{|c|}{$\begin{array}{l}\text { Single chamber } \\
\quad(\mathbf{n}=10)\end{array}$} & \multirow[b]{2}{*}{$P$ value } & \multicolumn{2}{|c|}{ FRS $(n=10)$} \\
\hline & Median & 025/075 & Median & $025 / 075$ & & Median & $025 / 075$ \\
\hline Preop Hb (g/L) & 143 & $138 / 148$ & 142 & $133 / 146$ & .353 & 143 & $140 / 149$ \\
\hline Preop Hct $(\%)$ & 42.5 & $40.0 / 44.0$ & 42.5 & $40.3 / 43.8$ & .853 & 42.5 & $40.5 / 43.8$ \\
\hline Minimum systemic $\mathrm{Hb}, \mathrm{CPB}(\mathrm{g} / \mathrm{L})$ & 85.0 & $79.8 / 94.4$ & 83.0 & $81.5 / 91.5$ & .912 & 88.0 & $79.3 / 94.8$ \\
\hline Minimum systemic Hct, CPB (\%) & 26.5 & $25.0 / 28.5$ & 26.0 & $25.5 / 28.2$ & .999 & 27.3 & $25.0 / 28.8$ \\
\hline PSB $\mathrm{Hb}(\mathrm{g} / \mathrm{L})$ & 74.9 & $60.6 / 100.3$ & 74.8 & $61.5 / 96.9$ & .971 & 74.9 & $57.9 / 115.3$ \\
\hline PSB volume (mL) & 418 & $269 / 631$ & 531 & $410 / 871$ & .166 & 304 & $190 / 554$ \\
\hline PSB volume vs hemodilution (mL) & 314 & $164 / 387$ & 327 & $223 / 466$ & .190 & 231 & $119 / 353$ \\
\hline PSB collection time (min) & 64.0 & $57.3 / 78.0$ & 70.5 & $60.2 / 92.3$ & .218 & 59.5 & $53.5 / 72.0$ \\
\hline Fat concentration in PSB $(\%)$ & 0.37 & $0.20 / 0.44$ & 0.21 & $0.17 / 0.37$ & .063 & 0.41 & $0.37 / 0.50$ \\
\hline Fat volume in PSB (mL) & 1.53 & $0.63 / 2.19$ & 1.53 & $0.96 / 2.09$ & .971 & 1.52 & $0.54 / 2.31$ \\
\hline
\end{tabular}

PSB, Pericardial suction blood; FRS, fat-reducing system; $H b$, hemoglobin; $H c t$, hematocrit; $C P B$, cardiopulmonary bypass. Fat in PSB includes fraction of plastic-bound fat. $P$ values refer to Mann-Whitney $U$ test.

for fat measurement, as well as in consideration of the measured PSB-fat concentration from the above single-chamber experiments. Blood was allowed to incubate for 10 minutes in each of the top and bottom chambers. All experiments were conducted at $22^{\circ} \mathrm{C}$. The analysis tested the difference in fat concentration between the measured input versus output of blood and did not require measurement of fat-to-plastic binding. For reference, the fat content in mediastinal drain blood was measured before being mixed with added fat. Experiments were designed to keep transfer steps of blood to an absolute minimum, a consistent use of materials, and applying reproducible and proper mixing procedures of blood samples. ${ }^{10}$

\section{Statistical Methods}

Median values and quartiles are given throughout. Nonparametric analyses were used including the Friedman analysis of variance, Wilcoxon signed rank test, Mann-Whitney $U$ test, and Spearman rank correlation.

\section{Results}

\section{Patient Demographics and Surgical Data}

The patient cohort showed normal characteristics for routine CABG procedures. The subdivision of patients into singlechamber bag or FRS demonstrated no significant differences (not shown). The recorded waste-suction bleeding was $325 \mathrm{~mL}$ (maximum $700 \mathrm{~mL}$ ). None of the patients required allogeneic blood during surgery. The median transfusion requirement during hospitalization was 2 units (Table 1). The patients from whom pericardial fat tissue and postoperative mediastinal blood were collected for experimental purpose included not only those having CABG procedures and showed a somewhat deviant demographic pattern (Table 1).

\section{Clinical PSB Data}

Table 2 shows PSB-related data subdivided into singlechamber and FRS and demonstrated no group differences in hemoglobin concentration: preoperatively, systemically during surgery, or in PSB. The FRS group contained 1 patient with outlier characteristics (Figure 2). This patient had a deviant and substantially higher PSB bleeding of $2.4 \mathrm{~L}$. Three patients had a PSB volume above $1 \mathrm{~L}$. The described outlier patient partly affected the recorded data in Table 2 with respect to PSB characteristics. The recorded PSB fat volume was identical in the two groups. However, there was a near significant $(P=.063)$ higher concentration of fat recorded in the FRS group (Table 2), which was solely due to a higher amount of plastic-bound fat. With the outlier excluded, this difference diminished $(P=.113)$. The PSB collection time was of the order of 60 minutes (Table 2). In the FRS group, 6 of 10 patients had the top chamber drained into the bottom chamber for storage and the top chamber refilled. However, in all but the described outlier patient was PSB returned in one portion at CPB weaning. There were effects from hemodilution, comparing the minimum systemic hemoglobin concentration versus its preoperative value $(P<.001)$. When PSB was corrected for hemodilution, the effective PSB bleeding was reduced from $418 \mathrm{~mL}$ to $314 \mathrm{~mL}(P<.001$, Table 2$)$.

\section{PSB Fat Characteristics}

The fat volume in PSB was $1.5 \mathrm{~mL}$, which corresponded to a concentration of $0.37 \%(n=20)$. The concentration showed no relationship to PSB volume, which was regardless of the outlier patient (Figure 2). However, there was a positive correlation between the amount of total fat and PSB volume, observed also with the outlier omitted $(P=.010)$. The recorded input PSB fat was the summation of that measured in blood and plastic-bound fat inside the collecting chamber. Plastic-bound fat was measured for the entire single-chamber bag, whereas for the FRS, only considering the top chamber. Plastic-bound fat showed no correlation to 


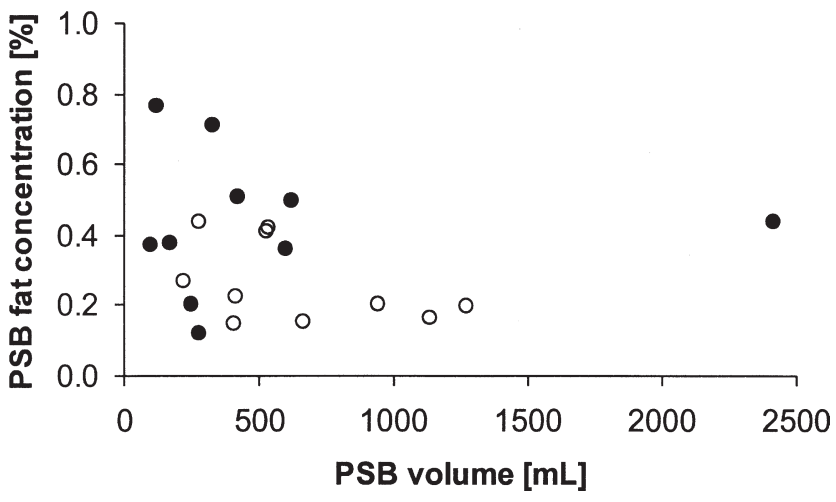

Figure 2. Relationship between pericardial suction blood (PSB) volume and fat concentration. Filled circles denote fat-reducing system and open circles denote single-chamber bag. An outlier is obvious and is discussed in the text.

PSB volume (data not shown) and accounted for $24 \%$ $(12 / 35)$ of the total input fat $(n=20)$.

Fat-reducing Efficacy of FRS in Clinical Study

The behavior of fat inside the FRS thus revealed effects of density separation and plastic binding (Figure 3). Bottomchamber blood was reduced in fat by $60 \%$ (42/70), as shown by comparing the output fraction of blood with the average of the two input samples from the top chamber $(P=.001$, Figure $3, a$ ). This comparison only considered bloodsuspended fat and not plastic binding. Fat reaching the bottom chamber continued to separate by density, which produced a significantly higher concentration of fat in the retained upper portion of blood compared with its lower fraction $(P=.017)$. Control venous blood had no recorded fat (Figure 3,a). Plastic-bound fat accounted for a significantly smaller portion than that contained in blood $(P=$ .017 , Figure $3, b)$. Plastic binding mainly occurred in the top chamber compared with that measured in the bottom chamber $(P=.005$, Figure $3, b)$. When both density separation and plastic binding were encountered together, the FRS gave a $73 \%(69 / 82)$ fat reduction. This reduction assumed that the upper layer of PSB in the bottom chamber was retained at drainage. Without this routine the reduction was 66\% (59/73), representing a less efficient result $(P=.022)$. Additional fat was eliminated due to the fact that not all PSB, and therefore fat, passed the FRS. The water-lock retained $21.4 \mathrm{~mL}$ and with an additional $25 \mathrm{~mL}$ retained in the bottom chamber the reduction rate was recalculated to $80 \%$ (72/86). The PSB storage also resulted in red cell sedimentation with a concentrating effect $(P=.001)$. The highest hematocrit value was seen for the bottomchamber output blood, a value equal to that of venous blood $(P=.445)$.
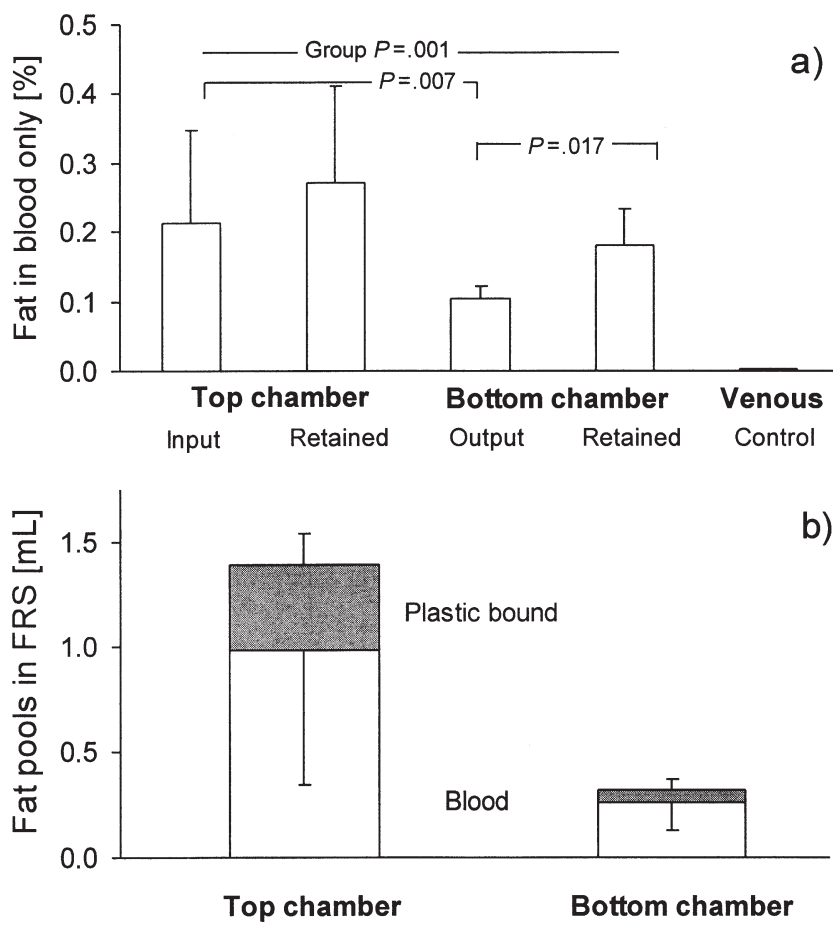

Figure 3. Fat-reducing system (FRS) fat distribution during clinical evaluation. a, Fat concentration in blood samples drawn from the following: top chamber during cardiopulmonary bypass, retained blood in top-chamber water-lock, first fraction of bottomchamber output blood, retained top-fraction blood in bottom chamber, and venous control, respectively. $b$, Pools of fat in FRS including plastic-bound portions. Indicated $\boldsymbol{P}$ values refer to group comparisons by the Friedman nonparametric analysis of variance and by the Wilcoxon signed rank test for post hoc comparison between single blood samples. Median values with quartiles are shown.

\section{Fat-reducing Efficacy of FRS in Experimental Study}

Postoperative mediastinal drain blood was mixed with heatextracted liquid pericardial fat. The mediastinal blood had a hematocrit value of $14.9 \%$ (12.4/17.6), numerically but not significantly lower than that recorded for input PSB $(P=$ $.093)$. In 5 of 12 patients, minor concentrations of fat were recorded in the mediastinal blood, with a maximum of $0.07 \%$. This endogenous fat was disregarded in the mixture with added pericardial fat aimed to yield $1.25 \%$ and did not affect the results. However, this mixture was recorded to contain only $1.00 \%$ fat, owing to fat-to-plastic binding inside the mixing container. The FRS efficacy was simply calculated from the measured input versus output fat concentration, not requiring analysis of plastic binding. Bloodsuspended fat was evidently reduced $(P<.001$, Figure 4$)$, with an $83 \%$ (71/92) reduction rate encountering the retained volumes of blood in the top and bottom chambers, as described above. The upper blood layer in the bottom cham- 


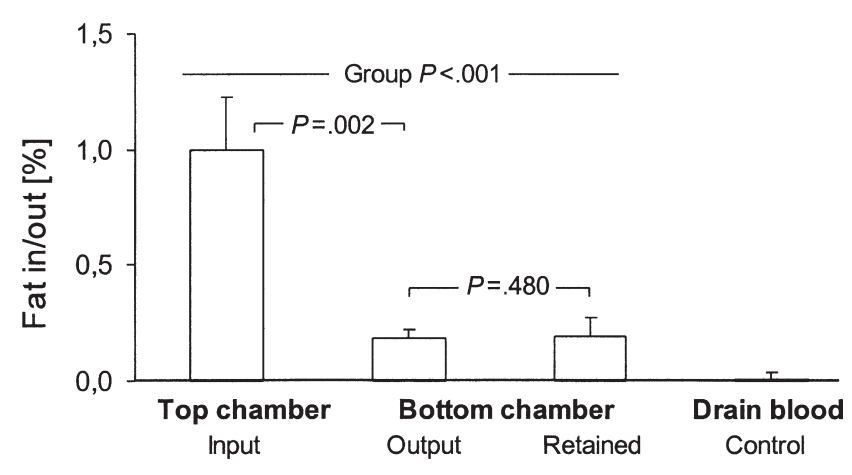

Figure 4. Fat-reducing system fat distribution under experimental conditions. See legend to Figure 3, a, for details.

ber ("retained") was not significantly higher in fat content versus the output fraction $(P=.480)$.

\section{Discussion}

It is obvious that PSB contains fat, assumed to mainly consist of triglycerides. ${ }^{13}$ The human body does not have biological mechanisms to rapidly handle nonemulsified fat of this sort. Fat becomes expelled into the ascending aorta and reaches the brain microcirculation within seconds. The present study demonstrated a fat volume of $1.5 \mathrm{~mL}$ suspended in about 0.4-L PSB. Although it has not been scientifically demonstrated that fat contributes to DBD, it is tempting to assume such a relationship in view of the presence of $\mathrm{SCADs}^{7}$ and the found impairment of capillary flow properties of fat-contaminated PSB plasma. ${ }^{8}$

Our study demonstrated that fat can be reduced in PSB during incubation by simple density separation and surface adsorption. The suggested FRS had two stacked chambers with an intersecting water-lock. The FRS yielded an $80 \%$ fat-reduction rate when evaluated clinically, and with a similar performance under experimental conditions. The FRS worked as clinically intended, patients tolerated the retained volume well, and no allogeneic blood was required during surgery. The ability to visualize PSB bleeding gave feedback to the perfusionist and surgeon, a phenomenon that may promote blood conservation. The FRS had no volume restrictions and fat accumulated during repeated filling.

Washing with a cell salvage device is the gold standard for fat removal in cardiac surgery ${ }^{9}$ with a proposed efficacy of $87 \% .^{14}$ However, an easier method is to discard PSB although this maneuver is counterbalanced by an increased need for allogeneic blood. Blood transfusions are associated with known risks, exemplified by transfusion errors and reactions, transmitted virus, or immunomodulation. ${ }^{15,16} \mathrm{An}$ intraoperative blood loss exceeding $0.4 \mathrm{~L}$ has been suggested to trigger allogeneic transfusion during $\mathrm{CABG}$ pro- cedures $^{17}$ and could potentially be affected by discarding PSB. It therefore seems reasonable to suggest that PSB should be separated from direct CPB return and instead be temporarily held to decide strategy for its use, as accomplished by the FRS. The proposed system may also serve as a complement to other fat-reducing devices.

The cell salvage device has obvious benefits but is costly and cumbersome, which may hamper feasibility. An important aspect of the cell salvage device is the removal of inflammatory mediators contained in plasma. ${ }^{18}$ On the negative side, there is loss of possibly important plasma components. A simpler alternative is a fat-reducing filter within the PSB suction line. However, such filters have been questioned because of a limited $40 \%$ fat removal, partly owing to saturation. ${ }^{12,19}$ Stacked filters may improve the efficacy, as suggested by Kaza and coworkers, ${ }^{20}$ with additive effects from the integrated cardiotomy-reservoir filter. Conversely, filters may trigger complement activation in drain blood. ${ }^{21}$ It is difficult to compare the results of previous reports owing to their variability in used fat-quantifying methods, exemplified by semiquantitative recordings versus the counting of fat globules only. ${ }^{14,20}$ Our study used a metric centrifugation technique. Of major importance is how blood samples are collected, mixed, and handled, as fat separates fast in blood, and how fat globules disperse or merge during these procedures. ${ }^{10}$ Plastic binding must also be considered. ${ }^{10}$ The experimental part herein was designed to mimic the clinical situation. Heat-extracted pericardial fat was used to resemble electrocautery melting and mixed with mediastinal drain blood. Our study confirmed that fat adheres to plastic surfaces. This suggests that the cardiotomy reservoir indeed participates in fat reduction. Jewell and coworkers ${ }^{14}$ proposed a $45 \%$ fat reduction by this mechanism. This phenomenon was here demonstrated by a $24 \%$ binding of input fat to plastic walls. A similar percentage was observed experimentally during blood-fat mixing in a plastic container. Thus, with the FRS connected in series with a routine cardiotomy reservoir, a higher fat-reducing efficiency can be anticipated than that actually measured. Recalculated from the study of Jewell and coworkers, ${ }^{14}$ it is possible that these combined mechanisms will provide the FRS with a near $90 \%$ fat reduction before PSB enters the venous reservoir. Means to further improve the FRS performance may include an increased area for fat binding and use of temperature modulation. ${ }^{10,11}$

This study is limited from not studying the outcome in patients and the possible benefits of fat reduction in terms of DBD. However, such an ambition would require a substantially larger number of observations and is further complicated by the multifactorial nature of DBD. The present study aimed at describing the presence of fat in PSB only, and how fat can be reduced by simple means. The mecha- 
nism by which some fat escapes the FRS and the characteristics of this particular fat remain to be investigated.

In conclusion, PSB contains fat, although its clinical relevance remains to be elucidated. It is here suggested that PSB should be collected to allow decision making regarding its use. The proposed FRS was meant to provide this feasibly, while at the same time offering an effective fat reduction nearly comparable with that of a cell salvage device.

We are grateful to Mrs Berith Lundström for skilled laboratory assistance and to Dr Michael Haney for comments on language.

\section{References}

1. Ahonen J, Salmenpera M. Brain injury after adult cardiac surgery. Acta Anaesthesiol Scand. 2004;48:4-19.

2. Bucerius J, Gummert JF, Borger MA, Walther T, Doll N, Onnasch JF, et al. Stroke after cardiac surgery: a risk factor analysis of 16,184 consecutive adult patients. Ann Thorac Surg. 2003;75:472-8.

3. Newman MF, Kirchner JL, Phillips-Bute B, Gaver V, Grocott H, Jones RH, et al. Neurological Outcome Research Group and the Cardiothoracic Anesthesiology Research Endeavors Investigators. Longitudinal assessment of neurocognitive function after coronary-artery bypass surgery. N Engl J Med. 2001;344:395-402. Erratum in: N Engl J Med. 2001;344:1876.

4. van Dijk D, Keizer AM, Diephuis JC, Durand C, Vos LJ, Hijman R. Neurocognitive dysfunction after coronary artery bypass surgery: a systematic review. J Thorac Cardiovasc Surg. 2000;120:632-9.

5. Caguin F, Carter MG. Fat embolization with cardiotomy with the use of cardiopulmonary bypass. J Thorac Cardiovasc Surg. 1963;46:665-72.

6. Moody DM, Bell MA, Challa VR, Johnston WE, Prough DS. Brain microemboli during cardiac surgery or aortography. Ann Neurol. 1990; 28:477-86

7. Brooker RF, Brown WR, Moody DM, Hammon JW Jr, Reboussin $\mathrm{DM}$, Deal DD, et al. Cardiotomy suction: a major source of brain lipid emboli during cardiopulmonary bypass. Ann Thorac Surg. 1998;65: 1651-5.
8. Appelblad M, Engstrom KG. Fat contamination of pericardial suction blood and its influence on in vitro capillary-pore flow properties in patients undergoing routine coronary artery bypass grafting. $J$ Thorac Cardiovasc Surg. 2002;124:377-86.

9. Kincaid EH, Jones TJ, Stump DA, Brown WR, Moody DM, Deal DD, et al. Processing scavenged blood with a cell saver reduces cerebral lipid microembolization. Ann Thorac Surg. 2000;70:1296-300.

10. Engstrom KG. Contaminating fat in pericardial suction blood: a clinical, technical and scientific challenge. Perfusion. 2004;19(Suppl 1): S21-31.

11. Engstrom KG, Appelblad M. Fat reduction in pericardial suction blood by spontaneous density separation: an experimental model on human liquid fat versus soya oil. Perfusion. 2003;18:39-45.

12. Engstrom KG. The embolic potential of liquid fat in pericardial suction blood, and its elimination. Perfusion. 2003;18(Suppl 1):69-74.

13. de Vries AJ, Gu YJ, van Oeveren W. The rationale for fat filtration during cardiac surgery. Perfusion. 2002;17:29-33.

14. Jewell A, Akowuah EF, Suvarna SK, Braidley P, Hopkinson D, Cooper G. A prospective randomised comparison of cardiotomy suction and cell saver for recycling shed blood during cardiac surgery. Eur J Cardiothorac Surg. 2003;23:633-6.

15. Stainsby D, Russell J, Cohen H, Lilleyman J. Reducing adverse events in blood transfusion. Br J Haematol. 2005;131:8-12.

16. Chelemer SB, Prato BS, Cox PM Jr, O'Connor GT, Morton JR. Association of bacterial infection and red blood cell transfusion after coronary artery bypass surgery. Ann Thorac Surg. 2002;73:138-42.

17. Engstrom KG, Appelblad M, Brorsson B. Mechanisms behind operating room blood transfusions in coronary bypass patients with insignificant bleeding. J Cardiothorac Vasc Anesth. 2002;16:539-44.

18. Amand T, Pincemail J, Blaffart F, Larbuisson R, Limet R, Defraigne JO. Levels of inflammatory markers in the blood processed by autotransfusion devices during cardiac surgery associated with cardiopulmonary bypass circuit. Perfusion. 2002;17:117-23.

19. de Vries AJ, Gu YJ, Douglas YL, Post WJ, Lip H, van Oeveren W. Clinical evaluation of a new fat removal filter during cardiac surgery. Eur J Cardiothorac Surg. 2004;25:261-6.

20. Kaza AK, Cope JT, Fiser SM, Long SM, Kern JA, Kron IL, et al. Elimination of fat microemboli during cardiopulmonary bypass. Ann Thorac Surg. 2003;75:555-9.

21. Dalen T, Bengtsson A, Brorsson B, Engstrom KG. Inflammatory mediators in autotransfusion drain blood after knee arthroplasty, with and without leucocyte reduction. Vox Sang. 2003;85:31-9. 